Journal of Education and Educational Development

8(2), 379-397, 2021

DOI: http://dx.doi.org/10.22555/joeed.v8i2.527

\title{
Mediating Role of Fluid Intelligence Between Working Memory and Academic Achievement of University Undergraduates: Does Gender Matter?
}

\author{
Sadia Niazi \\ University of Sargodha, Pakistan \\ Adnan Adil \\ University of Sargodha, Pakistan
}

\begin{abstract}
The present study examined the mediating role of fluid intelligence between working memory (WM) and academic achievement and tested the invariance of this model across gender in a random sample of university students $(N=560,228$ boys \& 332 girls). Heart and Flower task (Diamond, 2013) and Raven's Standard Progressive Matrices ${ }^{T M}$ Plus (Raven, 1998) were used to operationalize WM and fluid intelligence, respectively. Academic achievement was operationalized through CGPAs of students. Findings of the path analysis suggested that fluid intelligence mediated between WM and CGPA. Test of the model invariance indicated that fluid intelligence was a stronger predictor of academic achievement for boys as compared to the girls, which suggested that the indirect effect of WM on academic achievement through fluid intelligence was stronger for boys. Significant gender differences were observed as girls' mean scores on WM and academic achievement were higher than those of the boys.
\end{abstract}

Keywords: academic achievement, fluid intelligence, gender, working memory

\section{Introduction}

WM is the capacity of holding data in mind and working on it mentally while the information is no longer present perceptually. It is the ability to preserve and operate information in mind for a short period (Baddeley, 2002). According to Baddeley's (2000) model of executive functions, WM is an essential component of 
information processing and controlled attention that is involved in the recovery of information from long-term memory and for regulatory purposes. WM is crucial for creating a sense of learning material because it is always needed for holding the information in mind and linking them with recent and past events. It is essential for making the sense of spoken and written material, for doing mental math, mentally rearranging the items, and translating and incorporating the new information in action plans. WM just not enables the perceptual input but also helps to improve the conceptual clarity of the material (Diamond, 2012).

WM is one of the important cognitive associates of intelligence (Ackerman et al., 2005). Kane et al., (2005) proposed that WM is a cognitive ability that is strongly related to fluid intelligence. In fluid tasks, the WM is required to investigate the problems, observe the performance, and adjust the resolution policy as performance continues. WM helps in making mental representations while performing any analytical tasks (Broadway \& Engle, 2010). Fluid intelligence is a fundamental cognitive capacity that embroils abstract reasoning to solve unusual problems. Smolen and Chuderski (2015) demonstrated that fluid intelligence is strongly contingent on the student's effectiveness of working memory. The abovecited literature demonstrates WM as a positive predictor of fluid intelligence.

Identifying the precursors of students' academic achievement is an important research topic in psychological research for nearly one century (ChamorroPremuzic et al., 2005; Lubinski, 2004) and fluid intelligence has consistently been found as one of the most proximal predictors of academic achievement (Kuncel et al., 2001). Fluid intelligence is essential for solving problems in novel situations and performance in academic settings. The tests used to assess fluid intelligence are good predictors of academic success (Postlethwaite, 2011). Pind et al., (2003) observed that studies on the correlation between fluid intelligence and academic achievement determine moderate to a high level of correlations between them. Fluid intelligence elucidates a great part of individual differences in the varied types of human behavior and cognition. For example, highly intelligent people are superior in knowledge attainment, spatial navigation, and language ability, and they achieve high grades in their academics (Calvin et al. 2012).

WM is highly associated with a broad range of higher cognitive abilities such as problem-solving, reasoning, and learning. It is also related to academic 
achievement specifically in the domain of writing and reading (Abu-Rabia, 2003). WM aids in performing goal-directed behaviors in the face of distractions and interfering processes. The instruments used to assess WM evidenced the students' ability to acquire knowledge rather than their already learned material. WM is important in predicting IQ and academic achievement (Alloway \& Passolungh, 2011). Literature in psychology has discovered that scores on WM tasks are a valuable predictor of different cognitive abilities. For instance, scores on WM tasks are positively correlated with performance on comprehension, arithmetic, counting, and reasoning tasks (DeStefano \& LeFevre, 2004). WM scores are also a positive predictor of student's achievement in assessments of mathematics, science, and English (St Clair-Thompson \& Gathercole, 2006).

WM tasks predict reading attainment (Swanson \& Beebe-Frankenber-ger, 2004), mathematical achievement, and performance on arithmetic word problems (Swanson \& Sachse-Lee, 2001). There is considerable proof that WM plays an imperative role in the growth of academic skills, which in turn have a positive effect on their academic performance (Alloway \& Alloway, 2010; Gathercole et al., 2008). These threads of research evidence are signifying the importance of WM in academic achievement.

The above-cited literature suggested that WM and fluid intelligence are positive predictors of academic achievement. Numerous research studies showed that measures of WM significantly correlate with academic performance (Gathercole et al., 2004; Luo et al., 2003). For instance, Gathercole et al. (2004) found that achievement in mathematics and science was positively related to WM because these subjects assessed the analytical ability of the students (which is an integral part of fluid intelligence). Luo et al. (2006) postulated that WM helps in problem-solving and analytical reasoning (components of fluid intelligence), which in turn improves academic performance. These findings are also validated by other researchers (see Colom et al., 2005; Colom et al., 2006). For the growth of fluid intelligence, WM training is considered influential as it is short-term storage and information processing system (Baddeley, 2003). These studies imply that fluid intelligence may offer a causal explanation of the positive association between WM and academic achievement i.e., fluid intelligence may mediate between WM and academic achievement. 
This mediating relationship can be explained through the conceptual model of the current study presented in Figure 1.

\section{Figure 1}

The Conceptual Framework of the Present Study

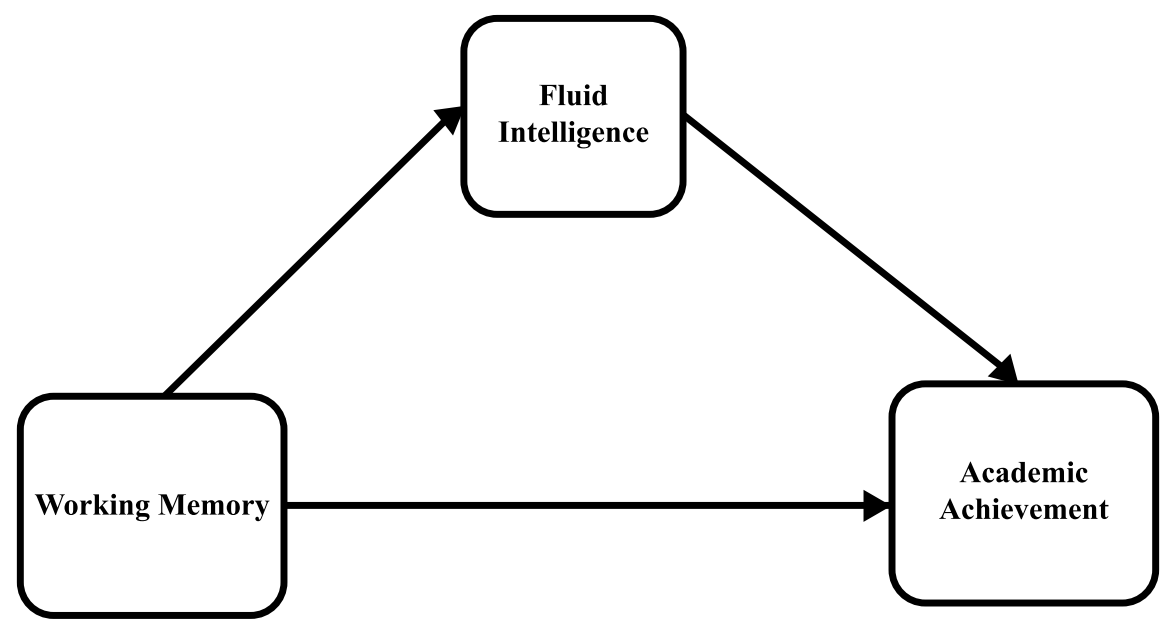

The conceptual model of the present study presented in Figure 1 has also been tested for its invariance across the gender. Gender differences in working memory, fluid intelligence, and academic achievement have been studied in the adult sample by some researchers and they reported mixed findings. For instance, Colom et al., (2000) found non-significant gender differences in fluid intelligence. However, Furnham et al., (1999) reported that men attained significantly higher scores on intelligence than did women. Similarly, Furnham and Buchanan (2005) and Johnson and Bouchard (2007) reported that men had higher levels of intelligence as compared to women. Researchers also reported gender differences in working memory; however, the findings are again mixed. Literature evidenced that men scored higher in WM tests that involved mathematical reasoning, on the other hand, women scored higher on tests of WM involving reading, writing, and civics (Hyde, 2005; Singh et. al., 2002). Naderi et al., (2010) investigated gender invariance in the relationship between fluid intelligence and academic achievement and found that for both men and women, the relationship between fluid intelligence and academic achievement was significant. 


\section{Research Questions and Hypotheses}

The present study sought the answers to the research question that how did working memory influences the academic achievement of university students. To answer this main research question, the present study formulated the following hypotheses:

$\mathrm{H}_{1}$ : WM will be a positive predictor of fluid intelligence (i.e., larger reaction time on the heart and flower task will be negatively related to fluid intelligence).

$\mathrm{H}_{2}$ : Fluid intelligence will be a positive predictor of academic achievement.

$\mathrm{H}_{3}$ : WM will be the positive predictor of academic achievement.

$\mathrm{H}_{4}$ : The relationship between WM and academic achievement will be mediated by fluid intelligence.

$\mathrm{H}_{5}$ : Significant gender differences will be observed in working memory, fluid intelligence, and academic achievement.

$\mathrm{H}_{6}$ : The proposed model of the present study will be variant across gender.

\section{Methodology}

\section{Sample}

The cluster sampling technique was used for the recruitment of the sample in the present study. For this purpose, all 36 teaching departments in the main campus of the University of Sargodha were conceived as clusters. By consulting a random number table, 18 departments were randomly selected. Out of these selected departments, all students of the $7^{\text {th }}$ semester of BS programs were included in the sample. Thus, a representative sample $(N=560)$ of undergraduates of the University of Sargodha was chosen that included 228 boys and 332 girls with an age range of 18 to 25 years $(M=21, S D=1.8$ years $)$.

\section{Instruments}

\section{Heart and Flowers Task}

Hearts and Flowers (Diamond, 2013) is the version of the Dots task introduced by Davidson et al. (2006) to measure the executive functioning of individuals. In this task, there are three blocks and participants are asked to touch the screen on the same or opposite side as they see the heart or flower on the screen, respectively. For measuring WM, only the first block (heart task) was used in the 
present study in which participants had to press on the same side of the screen on which the heart appeared and their reaction time was recorded. The lower the reaction time, the stronger the working memory and vice versa.

In the present study, the touch screen version was used where the stimulus was presented for 750 milliseconds on a 14-inch touch screen laptop with a screen resolution of 1366 × 786 through Presentation ${ }^{\circledR}$ software (Version 18.0, Neurobehavioral Systems, Inc.). Davidson et al. (2006) determined these time limits appropriate for age $(>7)$.

Alpha reliability of the EF composite was .63 (Sulik et al., 2018) and the retest reliability was moderate, with a mean $r=0.58$ (range $=0.41-0.99)$ (Traverso et al., 2015).

\section{Raven's Standard Progressive Matrices ${ }^{\text {TM }}$ Plus (SPM Plus)}

In the present study, Raven's Standard Progressive Matrices ${ }^{\mathrm{TM}}$ Plus (Raven, 1998) was used to measure the analytical intelligence of young adults. It comprised of five sets (A, B, C, D, and E), and each set further consisted of 12 matrices. The total score was computed by adding responses to each item. The internal reliabilities of SPM Plus ranged from .82 to .88 (Lynn et al., 2003).

\section{Academic Achievement}

Academic achievement was measured through the CGPA of students. The CGPAs were obtained from the offices of the controller of examinations of the respective departments.

\section{Findings}

In the present study, the data were analyzed through IBM SPSS and AMOS to test the proposed hypotheses of the present study. Descriptive statistics were computed for each of the measures. The mediation model was tested through AMOS. 


\section{Table 1}

Descriptions and Correlation among Variables of Present Study $(N=560)$

\begin{tabular}{lcccccc}
\hline Variable & M & SD & Skewness & $\mathbf{1}$ & $\mathbf{2}$ & $\mathbf{3}$ \\
\hline 1. WM & 5.2 & 1.1 & .54 & - & $-.16^{* *}$ & $-.09^{*}$ \\
2. IQ & 32 & 8.0 & -.73 & - & - & $.53^{* * *}$ \\
3. AC & 2.9 & .45 & -.01 & - & - & - \\
\hline
\end{tabular}

Note. $\mathrm{WM}=$ working memory ; IQ $=$ intelligence quotient $; \mathrm{AC}=$ academic achievement

$* \mathrm{p}<.05, * * \mathrm{p}<.01, * * * \mathrm{p}<.001$

aStandard error of skewness $=.10$

Table 1 displays descriptive statistics (i.e., means, standard deviations, and skewness) and intercorrelations for the variables of the present study. It shows that the variables of the present study are symmetrically distributed. The analysis depicted a significant correlation among present study variables in expected directions.

It is evident through fit indices that the proposed path model demonstrates an outstanding fit to the data with a non-significant chi-square value $\left(\chi^{2}(1)=.59\right.$, $p=.44)$. Other measures of data fit are also indicator of good fit as all of them are greater than cutoff point of $.95(\mathrm{CFI}=1, \mathrm{GFI}=.99, \mathrm{AGFI}=.99, \mathrm{NFI}=.99)$. $\mathrm{RMSEA}$ value of $.00\left(p_{\text {close }}=.92, L L=.00-U L=.10\right)$ and standardized RMR value of .01 also testify the fit of the proposed model. Thus, the proposed model of mediation is supported. The direct effects, indirect effects are presented in Table 2.

\section{Figure 2}

Mediating Role of Fluid Intelligence Between Working Memory and Academic Achievement.

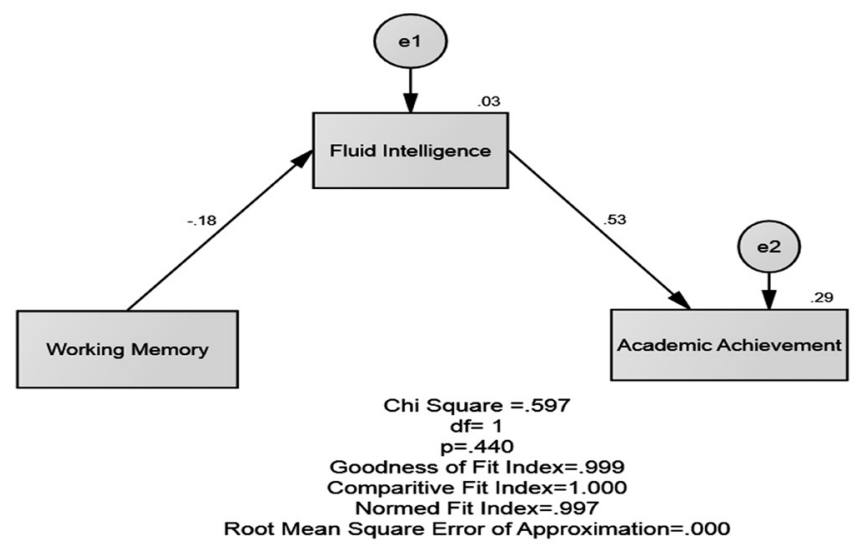


Figure 2 shows the path diagram of the proposed model of the present study. Standardized coefficients are also displayed along the paths. Multiple squared correlations are represented with the rectangles of endogenous variables.

\section{Table 2}

Standardized Path Coefficients of Direct and Indirect Effects

\begin{tabular}{lccc}
\hline \multirow{2}{*}{ Paths } & \multirow{2}{*}{$\mathbf{\text { 95\% CI }}$} \\
\cline { 3 - 4 } Gender $\rightarrow$ CGPA & & LL & UL \\
Working Memory $\rightarrow$ Fluid Intelligence & $-.12^{*}$ & -.20 & -.05 \\
Fluid Intelligence $\rightarrow$ CGPA & $-.15^{*}$ & -.22 & -.04 \\
Working Memory $\rightarrow$ Fluid Intelligence $\rightarrow$ CGPA & $-.08^{*}$ & -.12 & .59 \\
\hline
\end{tabular}

${ }^{*} \mathrm{p}<.05 ; * * \mathrm{p}<.001$

Table 3 displays significant direct effect of WM on fluid intelligence and it explained $2 \%$ variance in it $\left\{R^{2}=.02, p=.02(\mathrm{LL}=.00-\mathrm{UL}=.05)\right\}$, which provides support for the first hypothesis of the present study. The path coefficient is in a negative direction because a smaller reaction time is reflective of stronger working memory; therefore, a bigger reaction time (weak working memory) is negatively related to fluid intelligence. It also depicts that the direct effect of fluid intelligence on CGPA was positive and significant, which establishes the evidence for the support of the second hypothesis of the present study. No direct effect of working memory has been seen on academic achievement, which indicates that the third hypothesis of the present study is not supported. The indirect effect of WM on CGPA through intelligence is also significant, which supports the fourth hypothesis of the present study. These direct and indirect effects explained 30\% variance in CGPA $\left\{R^{2}=.30, p=.003(\mathrm{LL}=.24-\mathrm{UL}=.35)\right\}$. 


\section{Table 3}

Comparison of Standardized Path Coefficients of Direct and Indirect Effects Across Gender

\begin{tabular}{lcccc}
\hline Paths & $\mathbf{B}_{\text {Girls }}$ & $\mathbf{B}_{\text {Boys }}$ & $\Delta \boldsymbol{\beta}$ & $\mathbf{p}$ \\
\hline Working Memory $\rightarrow$ Fluid Intelligence & $-.17^{* *}$ & -.11 & -.059 & .49 \\
Fluid Intelligence $\longrightarrow$ CGPA & $.62^{* * *}$ & $.40^{* * *}$ & .22 & .000 \\
Working Memory $\rightarrow$ Fluid Intelligence $\rightarrow$ CGPA & -.045 & $-.11^{* *}$ & -.065 & .51 \\
\hline
\end{tabular}

${ }^{* *} p<.01,{ }^{* * *} p<.001$

\section{Figure 3}

The Moderating Role of Gender Between Fluid Intelligence and Academic Achievement

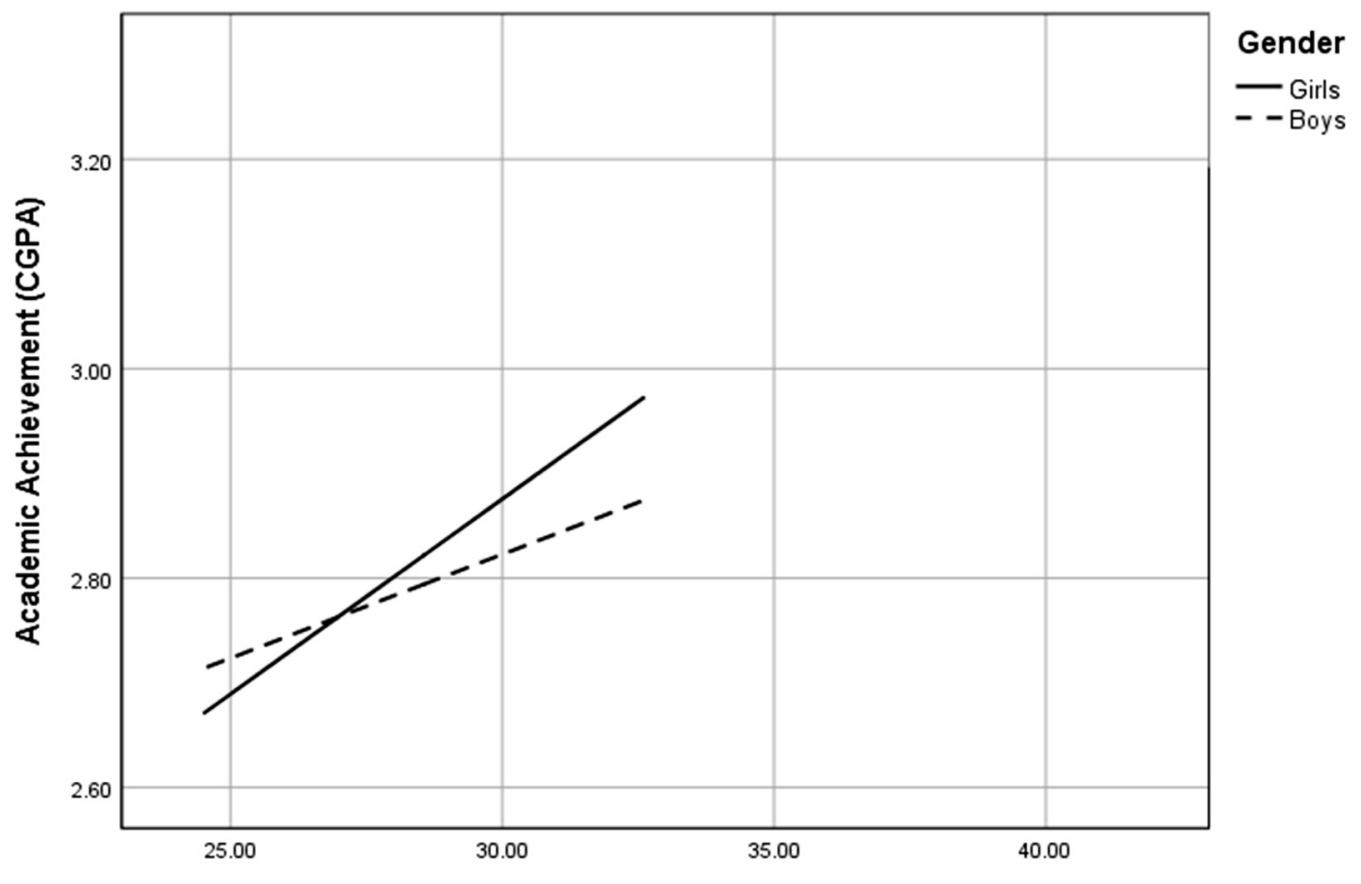

Fluid Intelligence

Results in Table 4 displayed gender differences in the present study variables i.e. working memory, fluid intelligence, and academic achievement. The results in 
Table 4 depicted significant gender differences in WM and academic achievement, which furnish the evidence for the support of the fifth hypothesis of the present study. However non-significant gender differences were evident in fluid intelligence.

\section{Table 4}

Gender Differences in the Variables of the Present Study $(N=560)$

\begin{tabular}{|c|c|c|c|c|c|c|c|c|}
\hline \multirow[t]{2}{*}{ Variables } & \multicolumn{2}{|c|}{ Girls } & \multicolumn{2}{|c|}{ Boys } & \multirow[t]{2}{*}{$t(558)$} & \multicolumn{2}{|c|}{$95 \%$ CI } & \multirow[b]{2}{*}{ Cohen's d } \\
\hline & M & SD & $\mathbf{M}$ & SD & & $\mathbf{L L}$ & UL & \\
\hline WM & 5.4 & 1.2 & 4.9 & 1.2 & $5.1 * * *$ & .31 & .700 & 0.4 \\
\hline IQ & 32.4 & 8.2 & 32.8 & 7.2 & 0.69 & .00 & .16 & .07 \\
\hline CGPA & 2.9 & .49 & 2.8 & .40 & $2.1^{*}$ & -1.8 & .85 & 0.2 \\
\hline
\end{tabular}

${ }^{*} p<.05,{ }^{* * *} p<.001$

\section{Discussion}

The present study commenced with the major goal to examine the impact of WM on fluid intelligence and academic achievement and to determine the mediating role of fluid intelligence between them. To measure WM, the percentage of correct responses on heart and flower, the first block (Heart task) was calculated by dividing the number of correct responses by the total number of responses. Trials with RTs faster than $250 \mathrm{~ms}$ were excluded for being too fast to have been in response to the stimulus. RTS 2 standard deviations above or below a participant's men were also excluded from analyses for being outliers.

Before assessing the relationships among the variables of the present study, the psychometric soundness of the instruments for measuring various constructs was examined. For this purpose, descriptive statistics and internal consistency levels for all scales were determined. The low to moderate values of standard deviations provide a clue that the means were a good approximation of their corresponding parameters. The skewness values of all the scales were also within the acceptable range, which suggested that the variable of the present study approximated the normal curve in their distributions. The correlations among variables of the present were in the expected directions.

The findings of the present study revealed a significant direct effect of WM on fluid intelligence. These findings are supporting the first hypotheses of the 
present study, which suggested that the WM would be the positive predictor of fluid intelligence. Unsworth, Fukuda, Awh, and Vogel (2014) reported similar findings by observing that reading and comprehending abilities are highly influenced by complex cognitive abilities such as WM. The complex WM is a positive predictor of higher-order cognitive abilities such as performance on SATs, vocabulary, and reading comprehension. A considerable amount of literature supports WM as the predictor of fluid intelligence. Fluid intelligence is the ability to solve novel problems through abstract reasoning, and it is positively correlated with various important skills such as learning, problem-solving, and comprehension. Engale and Kane (2004) claimed that highly intelligent people are better able to focus on relevant information and to effectively block distracting material in WM operation. Such people are active in the maintenance of information and its processing, which is fundamental for fluid reasoning. Chuderski et al., (2012) evidenced that students who scored high on measures assessing WM also scored high on a fluid intelligence test. The students with high WM are better able to retrieve items from their memory and actively maintained them (Unsworth \& Engle, 2007). Especially, this observation submits that individuals with high WM are superior at controlled search skills than low WM individuals (Unsworth, 2010). Usworth et al., (2009) claimed that students with higher WM performed better on intellectual tasks than did the students with low working memory. These findings are supporting the positive relationship between WM and fluid intelligence.

Fluid intelligence has also been considered an important predictor of various academic skills in an educational setting, which is deemed essential for academic achievement. These findings are supporting the third hypothesis of the current study that suggested fluid intelligence as a positive predictor of academic achievement. Conway et al., (2002) claimed that individuals with higher intelligence were likely to process information more quickly as compared to those with a lower level of intelligence. They further asserted that fluid intelligence positively predicted academic achievement. Various studies suggested fluid intelligence as a powerful predictor of academic achievement as it involves the ability to reason and understand intellectual problems efficiently (Bull \& Lee, 2014; Wilhelm et al., 2013).

The second hypothesis of the present study proposed WM as a positive predictor of academic achievement. The results of the current study did not support this hypothesis as WM did not demonstrate a significant direct effect on CGPA. 
WM is a center where all conscious information that has to process, lies. It is fragile in structure and is responsible for the temporary storage of information and its processing. For such a fragile system, it is not possible to keep in mind a large amount of information for a longer period. The information used by WM fades away very quickly or pushed by interfering stimuli. That is why WM independently can't predict academic performance (Klingberg, 2010). Nutley and Soderqvist (2017) claimed that WM training did not include actual teaching for academic performance, the student's performance was largely dependent on their other cognitive abilities such as fluid intelligence. Literature also supports the notion that WM only indirectly influences academic achievement through fluid intelligence (Harrison et. al, 2013; Jaeggi et al., 2014). These studies provide support for the fourth hypothesis of the present study which suggested the mediating effect of fluid intelligence between WM and academic achievement.

The fifth hypothesis of the current study was partially supported as the results demonstrated significant gender differences in WM and academic achievement, however, nonsignificant gender differences were observed in fluid intelligence. The findings of the current study depicted a higher level of WM and academic achievement in girls as compared to boys. Pertinent literature provides support for these findings of the present research, for instance, Speck et al., (2000) reported that while performing WM tasks, females preserved higher response accuracy with increasing task difficulty than males did. Using brain imaging, Speck et al. (2000) observed that the volume of brain tissue activation increased more rapidly in females than males, which led toward higher accuracy in response. The gender differences in academic achievement were also supported by Gutierrez et al., (2018) who claimed that girls mostly attained higher scores in their academics than boys did. Secondly, girls put more effort than boys do into attaining higher grades. González and De La Rica (2012) observed that in countries where the ratio of working women was on the rise, girls' academic performance was superior to that of the boys. Furthermore, gender roles may also play an important role in academic performance. Boys are more likely to aspire for the fame for which they may show dominance through rebellious attitude against their teachers, which make them feel more "masculine". On the other hand, girls always put more effort and try to be valued by their teachers to achieve a higher degree of self-esteem (Entwisle et al., 2007). 
The non-significant gender differences in fluid intelligence are also in line with pertinent literature, for instance, based on summated results from different countries. Later on, his view was supported on various grounds by many researchers i.e (Colom et al., 2000; Colom et al., 2002; Colom \& García-López, 2002).

The invariance across gender was tested and the results revealed significant gender differences in the second path of the conceptual model of the present study. The findings of the current study demonstrated that the relationship between fluid intelligence and academic achievement is stronger in girls as compared to boys. Similar findings have been reported by Deary et al., (2007) who noted non-significant gender differences in IQ but claimed a higher level of academic achievement in girls as compared to the boys. Fortin (2015) suggest that girl's good grades are a result of their higher attendance, high motivation level, and greater interest in education as compared to those of boys. There is mounting evidence that supports the gender gap in the academic achievement of students even after controlling their IQ level; for instance, researchers reported that girls can build strong relations with teachers, achieve high grades, and progress far better than boys do (Matthews et al., 2009). The above-cited literature about non-significant gender differences in fluid intelligence and significant differences in academic achievement are also supporting the moderating role of gender between fluid intelligence and academic achievement as can be observed in the second path of the structural model of the present study (see Figure 3). These results are supporting the sixth hypothesis of the present study i.e.; the proposed model of the present study would be variant across gender.

\section{Conclusion and Recommendations}

The current research inspected the potential role of gender in the mediation of fluid intelligence between WM and academic achievement in a random sample of students. The results revealed that fluid intelligence indeed mediated between WM and academic achievement, however, the path between fluid intelligence and academic achievement was moderated by gender. The positive direct effect of fluid intelligence on CGPA was stronger for girls as compared to the boys, which suggested a second-order moderation of the indirect effect of WM on academic achievement through fluid intelligence.

These findings are imperative for the assessment of students in their educational institutions and future occupations. Our findings suggest that WM has 
an only indirect effect on academic achievement through fluid intelligence, which indicates that instead of rote memorization of course contents and the prescribed syllabi, our educational system needs to enhance the analytical ability of our students if we want them to shine in terms of their academic performance. Therefore, our educational system must incorporate such pedagogical practices that may stimulate and enhance our students' fluid intelligence. This might have been achieved if our examination system elevates from the rote memorization or mere comprehension of the course contents and focus on the analysis, application, and synthesis of the core concepts of the prescribed syllabi. This also means that we have to upgrade our classroom practices and teaching methodologies so that we may develop an inquisitive mind, an analytical approach, and pragmatic orientation in our students enabling them to successfully solve the real-life challenges by efficient analysis of the situation and effective implementation of their academic learning.

The gender differences found in our results truly reflect why more and more girls are securing admission in our top academic institutions and why they outperform boys in academic achievement. The stronger positive relationship between fluid intelligence and academic achievement in girls suggests that as compared to the boys, girls might have been more likely to use their fluid intelligence in securing good grades and a better understanding of the course contents. This finding is an empirical blow to our indigenous gender stereotype that dictates boys as more capable and worthier of being invested in terms of academic careers. Our findings have shown that despite being equally intelligent to the boys, girls have more potential of demonstrating better academic performance, therefore, our society in general and our parents in particular need to shun off the gender stereotypes by providing equal opportunities for academic and career progressions to both girls and the boys.

\section{References}

Abu-Rabia, S. (2003). The influence of working memory on reading and creative writing processes in a second language. Educational Psychology, 23(2), 209-222.

Alloway, T. P., \& Alloway, R. G. (2010). Investigating the predictive roles of working memory and IQ in academic attainment. Journal of Experimental Child Psychology, 106(1), 20-29.

Alloway, T. P., \& Passolunghi, M. C. (2011). The relationship between working memory, IQ, and mathematical skills in children. Learning and Individual Differences, 


\section{1(1), 133-137.}

Baddeley, A. (2000). The episodic buffer: A new component of working memory? Trends in Cognitive Sciences, 4(11), 417-423.

Baddeley, A. (2003). Working memory: Looking back and looking forward. Nature Reviews Neuroscience, 4(10), 829-839.

Baddeley, A. D. (2002). Is working memory still working? European Psychologist, 7(2), 85-90.

Broadway, J. M., \& Engle, R. W. (2010). Validating running memory span: Measurement of working memory capacity and links with fluid intelligence. Behavior Research Methods, 42(2), 563-570.

Bull, R., \& Lee, K. (2014). Executive functioning and mathematics achievement. Child Development Perspectives, 8(1), 36-41.

Calvin, C. M., Deary, I. J., Webbink, D., Smith, P., Fernandes, C., Lee, S. H., ... \& Visscher, P. M. (2012). Multivariate genetic analyses of cognition and academic achievement from two population samples of 174,000 and 166,000 school children. Behavior Genetics, 42(5), 699-710.

Chamorro-Premuzic, T., Moutafi, J., \& Furnham, A. (2005). The relationship between personality traits, subjectively-assessed and fluid intelligence. Personality and Individual Differences, 38(7), 1517-1528.

Chuderski, A., Taraday, M., Nęcka, E., \& Smoleń, T. (2012). Storage capacity explains fluid intelligence but executive control does not. Intelligence, 40(3), 278-295.

Colom, R., \& García-López, O. (2002). Sex differences in fluid intelligence among high school graduates. Personality and Individual Differences, 32(3), 445451.

Colom, R., Abad, F. J., Rebollo, I., \& Shih, P. C. (2005). Memory span and general intelligence: A latent-variable approach. Intelligence, 33(6), 623-642.

Colom, R., García, L. F., Juan-Espinosa, M., \& Abad, F. J. (2002). Null sex differences in general intelligence: Evidence from the WAIS-III. The Spanish Journal of Psychology, 5(1), 29-35.

Colom, R., Juan-Espinosa, M., Abad, F., \& García, L. F. (2000). Negligible sex differences in general intelligence. Intelligence, 28(1), 57-68.

Colom, R., Rebollo, I., Abad, F. J., \& Shih, P. C. (2006). Complex span tasks, simple span tasks, and cognitive abilities: A reanalysis of key studies. Memory \& Cognition, 34(1), 158-171.

Conway, A. R., Cowan, N., Bunting, M. F., Therriault, D. J., \& Minkoff, S. R. (2002). 
A latent variable analysis of working memory capacity, short-term memory capacity, processing speed, and general fluid intelligence. Intelligence, 30(2), 163-183.

Davidson, M. C., Amso, D., Anderson, L. C., \& Diamond, A. (2006). Development of cognitive control and executive functions from 4 to 13 years: Evidence from manipulations of memory, inhibition, and task switching. Neuropsychologia, 44(11), 2037-2078.

Deary, I. J., Strand, S., Smith, P., \& Fernandes, C. (2007). Intelligence and educational achievement. Intelligence, 35(1), 13-21.

DeStefano, D., \& LeFevre, J. A. (2004). The role of working memory in mental arithmetic. European Journal of Cognitive Psychology, 16(3), 353-386.

Diamond, A. (2012). Activities and programs that improve children's executive functions. Current Directions in Psychological Science, 21(5), 335-341.

Diamond, A. (2013). Executive functions. Annual review of psychology, 64(1), 135-168.

Engle, R. W., \& Kane, M. J. (2004). Executive attention, working memory capacity, and a two-factor theory of cognitive control. Psychology of Learning and Motivation, 44(1), 145-200.

Entwisle, D. R., Alexander, K. L., \& Olson, L. S. (2007). Early schooling: The handicap of being poor and male. Sociology of Education, 80(2), 114-138.

Fortin, N. M., Oreopoulos, P., \& Phipps, S. (2015). Leaving boys behind gender disparities in high academic achievement. Journal of Human Resources, 50(3), 549-579.

Furnham, A., \& Buchanan, T. (2005). Personality, gender and self-perceived intelligence. Personality and Individual Differences, 39(3), 543-555.

Furnham, A., Rakow, T., Sarmany-Schiller, \& De Fruyt, F. (1999). European differences in self-perceived multiple intelligences. European Psychologist, 4(1), 131-138.

Gathercole, S. E., Durling, E., Evans, M., Jeffcock, S., \& Stone, S. (2008). Working memory abilities and children's performance in laboratory analogues of classroom activities. Applied Cognitive Psychology: The Official Journal of the Society for Applied Research in Memory and Cognition, 22(8), 10191037.

Gathercole, S. E., Pickering, S. J., Knight, C., \& Stegmann, Z. (2004). Working memory skills and educational attainment: Evidence from national curriculum assessments at 7 and 14 years of age. Applied Cognitive 
Psychology: The Official Journal of the Society for Applied Research in Memory and Cognition, 18(1), 1-16.

González de San Román, A., \& de La Rica, S. (2016). Gender gaps in PISA test scores: The impact of social norms and the mother's transmission of role attitudes. Economy of Transport and Port Logistics, 34(1).79-108.

Harrison, T. L., Shipstead, Z., Hicks, K. L., Hambrick, D. Z., Redick, T. S., \& Engle, R. W. (2013). Working memory training may increase working memory capacity but not fluid intelligence. Psychological Science, 24(12), 2409-2419.

Hyde, J. S. (2005). The gender similarities hypothesis. American Psychologist, 60(6), 581-592.

Jaeggi, S. M., Buschkuehl, M., Shah, P., \& Jonides, J. (2014). The role of individual differences in cognitive training and transfer. Memory \& Cognition, 42(3), 464-480.

Johnson, W., \& Bouchard Jr, T. J. (2007). Sex differences in mental abilities: g masks the dimensions on which they lie. Intelligence, 35(1), 23-39.

Kane, M. J., Hambrick, D. Z., \& Conway, A. R. (2005). Working memory capacity and fluid intelligence are strongly related constructs. Psychological Bulletin, 131(1), 66-71.

Klingberg, T. (2010). Training and plasticity of working memory. Trends in Cognitive Sciences, 14(7), 317-324.

Kuncel, N. R., Hezlett, S. A., \& Ones, D. S. (2001). A comprehensive meta-analysis of the predictive validity of the graduate record examinations: implications for graduate student selection and performance. Psychological Bulletin, 127(1), 162-181.

Liberman, N., \& Trope, Y. (1998). The role of feasibility and desirability considerations in near and distant future decisions: A test of temporal construal theory. Journal of Personality and Social Psychology, 75(1), 5-18.

Luo, D., Thompson, L. A., \& Detterman, D. K. (2003). The causal factor underlying the correlation between psychometric $\mathrm{g}$ and scholastic performance. Intelligence, 31(1), 67-83.

Luo, D., Thompson, L. A., \& Detterman, D. K. (2006). The criterion validity of tasks of basic cognitive processes. Intelligence, 34(1), 79-120.

Lynn, R., \& Irwing, P. (2004). Sex differences on the progressive matrices: A metaanalysis. Intelligence, 32(5), 481-498.

Lynn, R., Pullmann, H., \& Allik, J. (2003). A new estimate of the IQ in Estonia. 
Perceptual and Motor Skills, 97(2), 662-664.

Marcenaro-Gutierrez, O., Lopez-Agudo, L. A., \& Ropero-García, M. A. (2018).

Gender Differences in Adolescents' Academic Achievement. Young, 26(3), 250-270.

Matthews, J. S., Ponitz, C. C., \& Morrison, F. J. (2009). Early gender differences in self-regulation and academic achievement. Journal of Educational Psychology, 101(3), 689-704.

Naderi, H., Abdullah, R., Aizan, H. T., \& Sharir, J. (2010). Intelligence and academic achievement: An investigation of gender differences. Life Science Journal, 7(1), 83-87.

Pind, J., Gunnarsdóttir, E. K., \& Jóhannesson, H. S. (2003). Raven's Standard Progressive Matrices: New school age norms and a study of the test's validity. Personality and Individual Differences, 34(3), 375-386.

Postlethwaite, B. E. (2011). Fluid ability, crystallized ability, and performance across multiple domains: A meta-analysis. (published $\mathrm{PhD}$ dissertation). University of Iowa. https://doi.org/10.17077/etd.zopi8wvs.

Raven, J., Raven, J. C., \& Court, J. H. (1998). Raven's progressive matrices and vocabulary scales. Oxford psychologists Press.

Singh, P., Lin, T., Mueller, E. T., Lim, G., Perkins, T., \& Zhu, W. L. (2002). Open Mind Common Sense: Knowledge acquisition from the general public. In OTM Confederated International Conferences" On the Move to Meaningful Internet Systems" (pp. 1223-1237). Springer.

Smoleń, T., \& Chuderski, A. (2015). The quadratic relationship between difficulty of intelligence test items and their correlations with working memory. Frontiers in Psychology, 6(1), 1270-1280.

Speck, O., Ernst, T., Braun, J., Koch, C., Miller, E., \& Chang, L. (2000). Gender differences in the functional organization of the brain for working memory. Neuro Report, 11(11), 2581-2585.

St Clair-Thompson, H. L., \& Gathercole, S. E. (2006). Executive functions and achievements in school: Shifting, updating, inhibition, and working memory. The Quarterly Journal of Experimental Psychology, 59(4), 745-759.

Sulik, M. J., Haft, S. L., \& Obradović, J. (2018). Visual-Motor Integration, Executive Functions, and Academic Achievement: Concurrent and Longitudinal Relations in Late Elementary School. Early Education and Development, 40(13), 1-15.

Swanson, H. L., \& Beebe-Frankenberger, M. (2004). The relationship between working memory and mathematical problem solving in children at risk and not at risk for 
serious math difficulties. Journal of Educational Psychology, 96(3), 471-491.

Swanson, H. L., \& Sachse-Lee, C. (2001). Mathematical problem solving and working memory in children with learning disabilities: Both executive and phonological processes are important. Journal of Experimental Child Psychology, 79(3), 294321.

Traverso L, Viterbori P and Usai MC (2015) Improving executive function in childhood: evaluation of a training intervention for 5-year-old children. Frontier Journal of Psychology, 6(1), 525-530.

Unsworth, N. (2010). On the division of working memory and long-term memory and their relation to intelligence: A latent variable approach. Acta Psychologica, 134(1), 1628.

Unsworth, N., \& Engle, R. W. (2007). The nature of individual differences in working memory capacity: Active maintenance in primary memory and controlled search from secondary memory. Psychological Review, 114(1), 104-110.

Unsworth, N., Brewer, G. A., \& Spillers, G. J. (2009). There's more to the working memory capacity-fluid intelligence relationship than just secondary memory. Psychonomic Bulletin \& Review, 16(5), 931-937.

Unsworth, N., Fukuda, K., Awh, E., \& Vogel, E. K. (2014). Working memory and fluid intelligence: Capacity, attention control, and secondary memory retrieval. Cognitive Psychology, 71(1), 1-26.

Wilhelm, O., Hildebrandt, A., \& Oberauer, K. (2013). What is working memory capacity, and how can we measure it? Frontiers in Psychology, 433(4), 243-250. 